\title{
El uso del hiyab a la luz de los nuevos tiempos y su relación con los DD.HH
}

The use of hijab in the light of modern times and its relationship with Human Rights

\author{
Alejandra Torres \\ alejandratm10@gmail.com \\ Universidad de Chile
}

\section{Resumen}

La religión islámica ha generado y sigue generando debates. Esta vez es la prohibición del velo islámico (hiyab) en algunos países europeos, especialmente Francia y España, ambos con un alto porcentaje de inmigrantes, pero también de ciudadanos islámicos que exigen que sus derechos fundamentales se respeten. Es en este punto donde chocan principalmente las posturas a favor de su prohibición, ya que sería inconstitucional que un Estado se manifestara en contra de su uso, obligando a las mujeres a no cubrir sus cabellos, atentando contra la libertad de manifestar públicamente su religión. Es en este debate en que gira esta ponencia, describiendo distintas posturas de feministas laicas y musulmanas, además de intelectuales que se cuestionan si la utilización del velo es la que atenta contra los derechos humanos o su prohibición.

Palabras Claves: Hiyab - Derechos Humanos.

\begin{abstract}
The Islamic religion has generated and continues to generate discussions. This time it is the prohibition of the headscarf (hiyab) in some European countries, especially France and Spain, both with a high percentage of immigrants, but also of Islamic citizens who demand that their fundamental rights are respected. This is the point where they hit mainly stances in favor of a ban, as it would be unconstitutional for a State will vote against its use, forcing
\end{abstract}


women to not cover their hair, attacking freedom to express publicly his religion. It is in this debate in that turns this presentation, describing various positions of secular and Muslim feminist, as well as scholars are questioning whether the use of the veil is the that violates the human rights or prohibition.

Keywords: Hiyab - Human Rights

"Hay muchos tipos de velos. El velo religioso que empezó con el judaísmo, se extendió a la cristiandad y después al Islam.

Después, está el velo de la mente, que se ocupa de poner los medios de comunicación y los periodistas para que la gente no sepa lo que pasa. El tercer velo, que yo llamo el velo posmoderno, es el maquillaje. El más serio es el velo de la mente(....). ${ }^{1}$

La escritora y siquiatra egipcia Nawal al Saadawi señala que el velo más difícil de quitar es el de la mente y no podemos dejar de coincidir con ella, pues cada vez que escuchamos noticias del Medio Oriente nuestra mente de manera casi inconsciente lo relaciona con país musulmán y por lo tanto con violencia, muerte e inestabilidad política, sin darnos tiempo de reflexionar sobre el proceso que está atravesando y las causas que llevaron a esa situación o si efectivamente dicha relación existe. Los medios de comunicación en general y nuestro poco interés en conocer en particular, nos llevan a acumular una serie de prejuicios sobre el Islam y sobre los países árabes.

Para facilitar nuestra comprensión tendemos a dividir el mundo en dos, Occidente y Oriente, en el primero supuestamente se desarrolló la democracia, la tolerancia, la

\footnotetext{
${ }^{1}$ Parte de una entrevista a la escritora egipcia Nawal al Saadawi, extraído del libro El burka como excusa: Terrorismo intelectual, religioso y moral contra la libertad de las mujeres de Wassyla Tamzali.
} 
racionalidad, entre otras cualidades "civilizadas" y en Oriente todos los antónimos, lo malo, el lado oscuro. El mundo llamado Occidental juzga en base a sus propias categorías y conceptos al mundo llamado Oriental. Es por ello que uno de los debates que se producen y que de vez en cuando aparecen en documentales, tesis, paper, diarios, etc. es el lugar que ocupa la mujer, su difícil situación al ser condenada a cubrirse parcial o totalmente. Dependiendo del país la crítica es más o menos abundante, pero ningún estado musulmán se escapa. La pregunta de las feministas "occidentales" es por qué debe utilizar el velo la mujer y cubrir su cuerpo. ¿Por qué no tiene el poder de decidir? Suponiendo de antemano que la utilización del velo es una imposición masculina. Por otra parte, otros argumentan que obligar a las musulmanas a utilizar el velo atenta contra los derechos humanos de las mujeres y debe prohibirse su uso. Sin embargo, es ahí donde radica nuestra pregunta ¿es la utilización del velo la que atenta contra los derechos humanos o es su posible prohibición?

Durante los años 70, se masificó el uso del hiyab. La proliferación de esta prenda está marcada por el declive de proyectos revolucionarios y el surgimiento de los movimientos islamistas, que pretenden tomar al Islam como base y volver a los tiempos del profeta, lo que estaría estrechamente ligado a la visión que tiene de la mujer y la regulación de su cuerpo. La palabra hiyab procede de la raíz hayaba, que tiene, entre otras acepciones, la de "ocultación".

Algunos autores, como Ángeles Ramírez, han señalado que su utilización es una forma de resistencia que permite mantener su identidad y creencia, por lo tanto las mujeres militantes optan por el pañuelo, transformándose su uso en una contrahegemonía. En ese sentido, el pañuelo ha cumplido la misión de reforzar la identidad tanto hacia el exterior como el interior, es decir frente a los no militantes como a sus pares, reivindicando un papel político dentro de las organizaciones (Ramírez, 2011).

\footnotetext{
2 "El concepto de hiyab es tridimensional y las tres coinciden muy a menudo. La primera es visual: sustraer la mirada. (...) La segunda es espacial: separar, establecer un umbral (...) Y, por último, la tercera es ética: incumbe al dominio de lo prohibido (...) Un espacio oculto por el hiyab es un espacio prohibido". Fatima Mernisi. El harén Político. Ediciones del Oriente y del Mediterráneo. 1999. Madrid.
} 
Por su parte, la feminista iraní Valentine Moghadam advierte que:

El velamiento voluntario no es necesariamente expresión de filiación con, o de apoyo a, un movimiento islámico político, sino más bien de forma paradójica representa el rechazo de la autoridad parental o patriarcal entre mujeres jóvenes rebeldes. Éste puede ser de modo especial el caso de las jóvenes de familias no tradicionales -por ejemplo, palestinas, argelinas o tunecinas- que al ponerse el hiyab aspiran a una autonomía personal y a una apariencia más seria, sobre todo en colegios mixtos ${ }^{3}$.

Para Tariq Ramadan la situación es clara y no hay términos medios "imponer el velo a una mujer es antiislámico y obligarlo a quitárselo es un atentado a los derechos humanos" (Ramadan, 2011, p.121). Así como él, Fatima Mernissi, Wassyla Tamzali, Souad El Hadri, entre otros, aclaran que el velo no es exclusivo de los musulmanes, hebreas y cristianas también lo utilizaban. Su uso pasó de ser una costumbre para protegerse del viento a convertirse en un objeto cargado de simbolismo (Samhan, 2005). De hecho, tendemos a hacer una conexión entre el pañuelo y fundamentalismo islámico. Cuando ocurre aquello, algunos países ven la oportunidad de actuar como en el pasado y tratar a los musulmanes como colonias suyas, creyendo que su misión es salvar a las mujeres de su propia cultura, de la cultura de los "otros", utilizando el instrumento jurídico como un dispositivo de este salvamento (Ramírez, 2011, p.82), como ha sido el caso de Francia, España, y en menor medida Alemania.

La situación se vuelve aún más compleja cuando se está hablando de un país catalogado como "eje del mal", en otras palabras, contrario a las políticas de Estados Unidos. En ese caso, se ha convertido en banderas de lucha los derechos de las mujeres para "hacer pasar acciones bélicas por santas cruzadas por los derechos humanos” (Ramírez, 2011, p.39). Se va tornando cada vez más violenta la manera de imponerse a los otros, las supuestas defensoras de la paz y la salvación de las almas, como son las religiones, vuelven a

\footnotetext{
${ }^{3}$ El velo islámico y el velo occidental. Disponible en http://estambul.wordpress.com/2010/02/12/el-veloislamico-y-el-velo-occidental/
} 
convertirse en armas más eficaces para velar las mentes, dividir a las personas y estigmatizar dos mundos (Samhan, 2005).

El énfasis aquí, independiente de si el velo es exclusivo o no del Islam, es su utilización y no su función dentro de la espiritualidad musulmana. Pareciera ser que los que apoyan el hiyab, suponen que la mujer no está siendo aislada, sino que la finalidad es regular las relaciones entre hombres y mujeres en la cotidianidad y de acuerdo a los preceptos islámicos, interpretados por las distintas escuelas jurídicas. Dicha interpretación coloca énfasis en distintos aspectos, no obstante, Asma Lamrabet, señala que el Qur'an en sí no hace distinciones entre hombres y mujeres, son las tradiciones sociales y las costumbres tan arraigadas las que marcan la diferencia y el Islam no ha podido liberarse del machismo que caracteriza el mundo árabe (Samhan, 2005).

Lo anterior nos lleva a cuestionarnos dónde debe estar el acento, ¿en la utilización del velo o en la defensa de los derechos humanos? Se supone que mientras no sea una imposición, sino que sea producto de una decisión personal, el velo es aceptable. Pero ¿forma parte del compromiso religioso o de la voluntad de demostrar el poder de los hombres sobre las mujeres? Para la filósofa francesa Michèle le Doeuff, a las mujeres musulmanas se las ha hecho responsables de mantener la identidad utilizando el velo, mientras que a los hombres se les permite la vestimenta "occidental", por lo que se demostraría que no es la identidad lo que se preserva sino el control. Sin embargo, al obligar a una mujer a quitarse el velo también se está ejerciendo un tipo de dominación, que viene desde fuera de su comunidad, y por lo tanto es recibido de manera mucho más violenta.

Normativizando el cuerpo de los otros se hace evidente la relación de dominación, ya que se está imponiendo un modo de representación, a través de la implantación de una imagen a la que el sujeto tiene que parecerse o asimilarse: no hay que o hay que llevar el pañuelo. Las mujeres son presentadas como precaria y constantemente situadas en el límite de lo legal con lo ilegal. En los casos en los que se establece la restricción del 
hiyab en la diáspora musulmana se muestra, además, que esa cultura de los otros es atrasada, puesto que se le adjudica al pañuelo un significado de desigualdad entre hombres y mujeres (Ramírez, 2011, p. 144).

Una prenda tan sencilla y frágil, se convierte en el símbolo de lucha, la marca que hace la diferencia entre la civilización y la barbarie, con una clara carga política. Los "occidentales" pretenden liberar a las mujeres musulmanas de las ataduras arcaicas, sin pensar en que están pasando a llevar el derecho que tiene cada ser humano de manifestar libremente su religión ${ }^{4}$ y de no ser discriminado por ello. Lo que se pretende finalmente es salvar a las mujeres de los hombres de su propia cultura y presentar la imposición vestimentaria como un triunfo de la civilización, en otras palabras "la mujer del pañuelo no se parece a nosotros, por lo tanto, hay que asimilarla, arrancándoselo de la cabeza" (Ramírez, 2011, p.144).

Con consignas como evolución y progreso, igual que en el siglo XIX, algunos países buscan suprimir cualquier tipo de manifestación de religiosidad, definiéndose como laicos, generando conflictos constituciones, jurídicos y éticos. En el caso de Túnez, por ley se obligó a las mujeres a no usar el hiyab y hay policías que, cuya única función es vigilar y castigar a quienes no cumplan con lo dispuesto. La tunecina Fatma Labidi se manifiesta contraria a dicha ley y no entiende por qué se le prohíbe vivir su fe como ella quiere. Ella expresa: "Nosotros no andamos poniéndole velo a las no musulmanas ¿por qué, entonces, tienen que imponernos algo así?” (Samhan Ravenna-Ruiz, 2005, p.157).

Es un error que se vuelve a repetir, y que Ángeles Ramírez resalta:

\footnotetext{
${ }^{4}$ En la Declaración de los Derechos Humanos, en el artículo 18 expresa: Toda persona tiene derecho a la libertad de pensamiento, de conciencia y de religión; este derecho incluye la libertad de cambiar de religión o de creencia, así como la libertad de manifestar su religión o su creencia individual y colectivamente, tanto en público como en privado, por la enseñanza, la práctica, el culto y la observancia
} 
(...) la lucha contra la dominación de las musulmanas no puede llevarse a cabo desde la imposición-incluso jurídica- de un modelo emancipatorio liberal del que y en el que nunca han participado. Esta suerte de despotismo ilustrado feminista es efectivamente despótico, pero nunca podría ser feminista. (Ramírez, 2011, p.147).

Entre las feministas hay distintas posturas, por un lado están las laicas y por otro las islámicas. No existe un enfoque único en cuanto al uso del velo, mucho menos si es constitucional o no el prohibirlo. Las laicas creen que el origen de la discriminación de las mujeres está en el islam y piden la separación religión-Estado. De acuerdo a Claudia Morán (2013) las islámicas, en cambio, comparten que exista esta separación, pero para ellas el origen de la discriminación no radica en la religión, sino en la visión machista de los hombres, que son quienes han interpretado los textos. De acuerdo a Margot Badran (2010) los conceptos clave del feminismo islámico se basan en los principios coránicos de la igualdad de género y la justicia social, y lo que trata de hacer el feminismo islámico es avanzar en el mensaje islámico y expulsar los vestigios patriarcales.

Mirar el hiyab con una visión paternalista, pensando ingenuamente que se solucionan todos los males con su prohibición y promover la supremacía de un Estado laico, suponiendo que la neutralidad protege la heterogeneidad es volver al eurocentrismo del siglo XIX. De acuerdo a Tariq Ramadan (2011) algunos aprovecharon la oportunidad y transformaron la laicidad en una nueva religión, y justifican sus acciones en nombre de ella. Como ejemplo tenemos el caso de Francia, cuya larga tradición en la reafirmación de la laicidad del Estado y la identidad nacional, ha conducido hasta una normativa de prohibición absoluta del uso de símbolos religiosos en las escuelas públicas, preservando su neutralidad y así eliminando cualquier posibilidad de proselitismo religioso o político (Briones, 2009). A raíz de la expulsión de tres jóvenes que se negaron a quitarse el velo en 1989, el aquel entonces Ministro de Educación, Lionel Jospin, pide la intervención del Consejo de Estado, el cual emitió un dictamen, señalando que los alumnos lleven signos por los cuales se identifica su pertenencia a una religión no es por sí mismo incompatible con el principio de laicidad en 
la medida que constituye un ejercicio de su libertad de expresión y manifestación de sus creencias religiosas. El debate continuó con argumentos a favor y en contra, con avances y retrocesos, finalmente el 3 de julio de 2003 se conformó la Comisión de reflexión sobre la aplicación del principio de laicidad en la República Francesa. Dicha Comisión elaboró el denominado Informe Stasi que dentro de sus conclusiones destaca como elemento principal la reivindicación del principio de laicidad como elemento fundador de la República Francesa, el cual descansa sobre tres valores indisociables y necesarios para que todo ciudadano pueda sentirse reconocido en el seno de la República: la libertad de conciencia, la no discriminación religiosa y la neutralidad del poder político. A su vez, la Comisión intenta dar validez a su recomendación enfatizando que el derecho a manifestar las creencias religiosas no es un derecho absoluto y que cae dentro de las limitaciones aceptadas por las obligaciones internacionales en materia de derechos humanos, defendiendo además un cierto margen de apreciación para imponer este tipo de restricciones a derechos humanos (Briones, 2009).

En el caso de Francia, por lo tanto, se lucha contra la discriminación, pero a la vez, se promulga una ley que prohíbe a los estudiantes de las escuelas públicas exhibir símbolos de pertenencia religiosa o política, como por ejemplo cruces de gran tamaño, el velo o la kipá. Nuevamente se llega a una encrucijada y se cuestiona cuál es el límite de un estado que se dice neutral en materia religiosa, pero que a la vez debe respetar los derechos de las personas de manifestar su religión, entendiendo que la fe no solo abarca una dimensión interna y personal, sino que se extiende a una forma de vida, que identifican a una persona con otras donde comparten valores y principios. En cuanto a lo anterior el Tribunal Europeo de Derechos Humanos ha afirmado que:

La libre manifestación del derecho de libertad religiosa no es absoluta, aunque el derecho en sí mismo sea fundamental y atribuible a la dignidad de la persona, es decir, que el orden público y el respeto a los derechos de los demás constituyen un límite, aunque siempre debe ser interpretado en sentido restrictivo (Briones, 2009, p. 53). 
Pareciera ser entonces que antes que los derechos individuales, el Estado tiene la obligación de proteger los derechos y libertades de la sociedad en su conjunto con el fin de resguardar el orden público y mantener la paz. En España, por ejemplo, las musulmanas pueden reivindicar el uso del velo, siempre y cuando sea una manifestación de su derecho a la propia imagen, pero podría limitárseles legítimamente cuando existen intereses públicos o ajenos justificados para ello, en otras palabras, podría prohibírseles si la prenda provoca la desestabilización del orden público (Pérez, 2011). En el caso de Francia, muy similar al de España, los musulmanes estarían alterando el orden público y por lo tanto deben ser suprimidos sus derechos por el bien común. No obstante, y pese a que el Estado francés se legitima en su constitución laica, para Tariq Ramadan no es suficiente, ya que sus estudios lo han llevado a declarar que no existe nada en la laicidad que se oponga a la práctica libre y autónoma del Islam (Ramadán, 2011) y que por lo tanto lo que predomina es el miedo al aumento de inmigrantes de distintas etnias y religiones.

Todo lo anterior nos lleva a pensar que en el fondo este debate surge sólo como excusa que oculta el temor a lo desconocido, a lo distinto a ese otro que es aparentemente mi enemigo. Es más fácil dividir el mundo en blanco y negro, en oriente y occidente que detenernos a pensar si esa división es tan efectiva para comprender y si es real. Para Edward Said (2002) esa imagen de Oriente esta distorsionada, pues es solo una representación que ha hecho Occidente aludiendo a que Oriente no es capaz de representarse así mismo. Lo mismo ocurre con la discusión de si llevar o no pañuelo, en el fondo lo que está en juego, como dice Vargas Llosa (2003), son dos maneras distintas de entender los derechos humanos y el funcionamiento de una democracia y una excusa para actuar contra el otro y deslegitimarlo.

\section{Reflexiones finales}

El uso del hiyab, independiente de si es una prescripción religiosa o no, o si se utiliza por convicción espiritual o para reafirmar la identidad, o bien como símbolo de lucha, es la punta del iceberg de los conflictos que acompañan a los musulmanes y su interacción con 
otras religiones. Creer que la prohibición del hiyab en el ámbito público es equivalente a la liberación femenina, la superación de la desigualdad, la pobreza, brecha social, injusticia, violencia, y así a una serie de problemas que existen, demuestra cierta ingenuidad de nuestra parte. No, la eliminación del velo no convertirá al Islam en la religión del futuro, ni logrará la superación de los conflictos sociales, políticos y económicos. Si pensamos que el velo es el símbolo máximo de opresión, es que estamos viviendo aún en el siglo XIX y seguimos luchando contra la "barbarie", imponiendo conceptos, ideologías y sentidos a sujetos con distintas historias y formas de vida, sin darles de verdad el derecho a decidir y convirtiéndonos en ventrílocuos y hablando en nombre de los otros, suponiendo que eso es lo que ellos quieren. Como parafrasea Ángeles Ramírez a Marnia Lazreg “nadie debería atribuirse el derecho de hacer del pañuelo una bandera ni de obtener satisfacción de retirarlo, excepto las propias mujeres" (Ramírez, 2011, p. 147).

Recordemos las palabras de Nawal al Saadawi, el único velo que hay que hacer desaparecer es el velo de la mente, sin lugar a dudas es el más difícil de desprenderse.

El debate no termina aquí, si pretendemos tener la verdad e intentamos imponerla estaríamos transgrediendo los derechos fundamentales de otras personas, pero si se deja pasar quizás estemos siendo cómplices de una transgresión de igual manera. Para Mernissi el tema ya esta zanjado, cuando un periodista le preguntó por su hiyab ella respondió: "en lugar de preocuparse por lo que tengo sobre la cabeza, ¿por qué no se interesa por lo que tengo dentro de ella?” (Manuel, 2010)

\section{Bibliografía}

Aláez Corral, B. (2011). Reflexiones Jurídico-Constitucionales sobre la prohibición del velo islámico integral en Europa, UNED. Teoría y Realidad Constitucional, no 28, 483-520. 
Badran, M. (2010). Feminismo islámico en marcha. CLEPSYDRA: revista de estudios de $\begin{array}{lllll}\text { género } & y & \text { teoría } & \text { feminista, } & \text { 69-84. }\end{array}$ http://dialnet.unirioja.es/servlet/articulo?codigo=3367964\&orden=1\&info=link

Briones Martínez, I. (2009). El uso del velo islámico en Europa. Un conflicto de libertad religiosa y de conciencia1 Especial referencia a Francia, Alemania, Reino Unido, España e Italia. Anuario de Derechos Humanos. Nueva Época, $n^{o}$ 10, 17-82.

Cuesta, A. (2012). El velo islámico y el velo occidental. Publicado el 12 de febrero de 2012 http://estambul.wordpress.com/2010/02/12/el-velo-islamico-y-el-velo-occidental/

Macías Otón, E. (2008). La legislación reguladora del principio de laicidad en la escuela francesa, Anales de Derecho, nº26, 621-631.

Manuel A. (2010). No hay tela que cortar. Publicado el 7 de julio de 2010 http://www.paralelo36andalucia.com/tela-que-cortar/

Mernisi, F. (1999). El harén Político. Madrid: Ediciones del Oriente y del Mediterráneo.

Morán, C. Femen ha mostrado la caricatura del feminismo mal entendido. Publicado el 21 de julio de 2013. http:/goldmansachsisnotanaftershave.com/2013/06/21/femen-hamostrado-la-caricatura-del-feminismo-mal-entendido/comment-page-1/.

Pérez Álvarez, S. (2011). Marco Constitucional del uso del velo y del pañuelo islámico en la sociedad española contemporánea: ¿Señas de identidad ideológica y/o cultural? Foro: Revista de ciencias jurídicas y sociales, $\quad \mathrm{n}^{\mathrm{o}} \quad 13,139-187 . \quad$ En http://dialnet.unirioja.es/servlet/articulo?codigo $=3817458$

Said, E. (2002).Orientalismo. Madrid: Debate. 
Samhan Ravenna-Ruíz, F. (2005). Las hijas del Islam. Santiago: Mare Nostrum.

Ramadán, T. (2011). Mi visión del Islam occidental. Barcelona: Kairós.

Ramírez, A. (2011). La trampa del velo: el debate sobre el uso del pañuelo musulmán. Madrid: Catarata.

Vargas Llosa, M. (2003). El velo islámico. Publicado el 22 de junio de 2003. Diario El País de http://elpais.com/diario/2003/06/22/opinion/1056232807_850215.html. 